\title{
Do you know what your patient is thinking?
}

\author{
Rosamund Snow patient editor, The BMJ
}

The way GP surgery and hospital outpatient encounters are organised-limited time, the power relations in the room-means that many things are left unsaid. As a patient this frustrates me; it's a missed opportunity. I have a long term condition that means I see healthcare professionals a lot. I've experienced a range of attitudes and types of care: from care that was so good it still makes me smile in gratitude 20 years later to dangerously bad care that reduced me to angry sobbing once I'd left the clinic.

The only similarity in all these encounters is that I couldn't tell any of those doctors what I thought. All he or she will have noticed is a moderately compliant patient nodding along. Quite possibly the "bad" doctor thought he was doing a great job; quite possibly the "good" one had no idea he had turned my life around. In fact, the only time I told a healthcare professional what I was thinking - a wonderful emergency department nurse whom I thanked for making me feel safe in a frightening and difficult situation—she was shocked because she thought she'd been skimping on care through lack of time. Even then, because I was ill, I couldn't manage to put into words exactly what she'd done that was so good. (It was at least in part to do with what she did when she wasn't with me: the calm and respectful way she spoke to the terrified patient with dementia in the next bed made me feel safe.)

Though patients and carers are becoming more involved in the ongoing education of healthcare staff, we rarely have the chance to set the agenda for what we would like you to learn. In our new patient led and patient authored series, What Your Patient is Thinking, we hope to redress this balance a little. The points made will range from practical hints and tips for meeting needs specific to certain conditions through to challenges to the medical status quo. What they will all do is offer practical things you can do differently tomorrow as a result of reading what we have to say. You may not agree with the authors' views; you may already be doing the things they suggest. But at the very least we want to offer you the opportunity to find out what we might be thinking at those times when it's too difficult for us to tell you directly.

The series, running monthly at first, is part of The BMJ's patient partnership strategy (thebmj.com/campaign/patient-partnership). The first in the series may make some readers uncomfortable (doi:10.1136/bmj.g6845). Continuing professional development and continuing medical education points will be available to those doctors who want to take the formal opportunity to reflect on each piece. You can also send us a rapid response to give us your thoughts (thebmj.com/about-bmj/resources-readers/ responding-articles).

And finally, if you are a patient or carer reading this and you are inspired to write something in the new format, please read the guidelines for authors (thebmj.com/about-bmj/resourcesauthors/article-types) and get in touch. If you aren't confident in writing, but have useful things to say, we still want to hear from you. Tell us about the good as well as the bad; reassure as well as challenge. Doctors who come across as poor may just be unaware of what they do wrong. Excellent doctors need to know what makes them excellent, so they can keep on doing right.

Follow Rosamund Snow on Twitter @BMJPatientEd and discuss the series with the hashtag \#WYPIT.

Cite this as: $B M J$ 2015;350:h375 